scientific and personal memories without offering the reader too large a book. I have decided to write down the scientific development without too much ballast". But ho adds somewhat sadly, "Perhaps it will still be granted to me to write down my personal memories of my long life somewhat more extensively on a future occasion". My Life is the book he hoped to write and did; but he died while the volume was being printed.

Hahn's autobiography spans more than 80 years of personal history. Many of his notes were lost when his laboratory in Berlin-Dahlem was destroyed through $e$ nemy action in 1944. Hahn manifestly had an excellent memory to enable him to recall the many stories, conversations and impressions. From what he tells, tho reader can obtain a good picture of the kind and apparently simplo but tough and intelligent human being Hahn was. He had a charming sense of humour; typically ho calls himself a pretty "uneducated" Nobel laureate.

We are given a good idea of student life around 1900, of a chemist's service in the First World War and, in contrast to the latter, of the comparative inactivity of the German atomic scientists during the Second World War. Hahn could be called an anglophile, an attitude which, if anything, was enhanced by his experiences during internment at Godmanchester in 1945. Hore, on November 26, Hahn learned from the Daily Telegraph that he had been awarded the Nobol Prize.

His long partnership with Dr Lise Meitner and many other personal contacts with Jews havo made Hahn into a staunch anti-Nazi. His behaviour during the Nazi period gained him international respect which, probably even more than his reputation as discoverer of fission, enabled him to play the main part in rebuilding German science after the great defeat.

Hahn's story is interrupted by five intervicws which try to bring out points of general interest. Sir James Chadwick has contributed an execllent preface and Dr H. L. Schrader a valuable postscript. As the book is a translation from the German by Ernst Kaiser and Eithne Wilkins, it is surprising how many German words are misspelled. And why was the chemist Hahn called a physicist on the dust cover?

I wish to end this reviow with a quote: "It was in 1906, and the English journal Nature was having Rutherford photographed. The photographor did not like the first pictures ho had taken, because one couldn't sce Rutherford's cuffs on them. Now, Rutherford had no cuffs, so he borrowed mine. The photograph was published, complete with my cuffs, and I treasure it."

\section{Egon Bretscher}

\section{SUMMER SCHOOL PHYSICS}

\section{Physique Nucléaire/Nuclear Physics}

Edited by C. DeWitt and V. Gillet. Pp.xvi + 797. (Gordon and Breach: New York and London, November 1969.) $\$ 15 ; 150 s$.

SINCE 1951 annual summer schools of theoretical physics have been held at Les Houches in the French Alps under the auspices of the Université de Grenoble-Ecole d'été de Physique Théorique. Those are extensive courses lasting about eight weeks and attended by young research physicists from all parts of the world. Invariably, the lecturers are of high international reputation and the year 1968 was no exception.

The school in that year devoted itself to nuclear physics, and the book under review consists of detailed write-ups of all the twelve lecture courses.

The lecture courses are all pedagogical in nature, usually starting from well established theory and then moving on to recent developments in the field concerned. In general, they are complete in themselves, although unfortunately this is not true of the otherwise excellent course given by Professor M. Baranger on many-body theory which, on certain topics, refers the reader to notes of related lectures he gave at an earlier summor school (Varenna, 1967).

Summer schools (and even winter schools!) are now an established way of life for physicists and more of them seem to be held each year. It is also standard practice to publish the lectures given in some form or another. Frequently this has led to quite unsatisfactory compila. tions, hastily flung together and with a more than reasonable share of inaccuracies. This is not the case with this volume, and Professors C. DeWitt and V. Gillet are to be congratulated for editing it so carefully.

It is impossible in the space provided to review each of the lecture courses, but perhaps I might be allowed to pick out just one course for special mention, not because it was better than the rest but because it has a style and viewpoint which particularly appeal to me. 'This is the course by Professor H. J. Lipkin which deals with most of the currently exciting parts of elementary particle physics in a language familiar to the low energy nuclear physicist. It is a remarkable feat to be able to got over so many important and complicated ideas in such a simple way. All of the other courses aro equally good in their different ways and the volume is thoroughly recommended for anybody about to work or already working in the fields covered.

R. J. BLIN-STOYLE

\section{PULSE RADIOLYSIS}

\section{Pulse Radiolysis}

By Max S. Matheson and Leon M. Dorfman. (MIT Press Research Monographs in Radiation Chemistry, Vol. 1.) Pp. $x+202$. (MIT Press: Cambridge, Massachusetts, and London, 1969.) $110 \mathrm{~s}$.

IN the preface to this book the authors point out that the technique of pulse radiolysis is not only of value in its application to the problems of radiation chemistry, but, as a technique for the study of fast reactions, it has very wide application in the field of reaction kinetics. The authors for their part have been intimately involved in radiation chemical research over a long period and have been involved in the exploitation of the techniques of pulse radiolysis from its inception; thus they are exceptionally well qualified to write this text.

The early chapters provide a detailed description of the technology and methods used in pulse radiolysis and an account of the developments, such as the extension of the time resolution to the nanosecond region, which have taken place since the first experiments in 1961. The amount of detail presented suggests that the authors had potential users of the technique in mind when writing, and the very detailed lists of references certainly render it a valuable source-book from this standpoint. Some of the content is, however, perhaps superfluous for this class of rcader. For example, considerable space is allocated to simple treatments of kinetic data which are within the capabilities of the average second year undergraduate student.

The remaining chapters deal in considerable detail with the systems which have bcen studied by pulse radiolysis and the data are critically reviewed. The nature, reactivity and spectral characteristies of the many transient species - solvated electrons, free radicals, unusual valency states of metal ions and excited states of molecules-which have been studied by the tochnique are discussed, and a wealth of information is presented in tabular form. It is unfortunate that in some of these tables of rate constants, confusing and conflicting means of expressing the units are used which in some instances lead to errors of $10^{18}$ if the units are taken at their face value. Has a multiplier a different meaning when placed before the multiplicand, as in Table 7.12 , from that when placed after the multi- 